\title{
MÉDICO-DOCENTE: REFLETINDO SOBRE SUA PRÁTICA PEDAGÓGICA NO INTERNATO
}

José Antonio Nascimento Bressa, Raimunda Abou Gebran

Universidade do Oeste Paulista - UNOESTE, Programa de Pós-Graduação em Educação, Presidente Prudente, SP. Email: ragebran@hotmail.com

\section{RESUMO}

O trabalho docente do profissional médico no estágio curricular obrigatório (internato), traz reflexões e questionamentos sobre os dilemas existentes entre a sua atuação pedagógica e o atendimento ao doente. O objetivo da pesquisa foi analisar a ação do docente em sua prática pedagógica no internato, buscando compreender sua identidade, concepções e experiências educativas. Trata-se de pesquisa qualitativa (estudo de caso), envolvendo os docentes do internato de uma Universidade privada do interior do estado de São Paulo. Os procedimentos da pesquisa foram: aplicação de questionário, entrevista semiestruturada e observação da ação docente. A análise de dados (análise de conteúdo) buscou caracterizar a ação do médico-docente na construção de sua identidade profissional, desvelar as relações didático-pedagógicas e assistenciais no desenvolvimento das atividades, avaliar o processo didático-pedagógico, destacar os limites e possibilidades no internato. A triangulação entre as ações do médico-docente, o paciente e o aluno descortinará essas inter-relações e possibilitará o desenho de novas metodologias de ensino na prática do internato.

Palavras-chave: Integração docente assistencial, internato, preceptor

\section{MEDICAL-TEACHER: REFLECTING ON HIS PEDAGOGICAL PRACTICE ON THE INTERNSHIP}

\begin{abstract}
The teaching work of the medical professional in the compulsory curricular internship, brings reflections and questions about the dilemmas existing between his pedagogical performance and patient care. The objective of the research was to analyze the action of the doctor-teacher in his daily pedagogical practice, seeking to understand his identity, conceptions and educational experiences. This is a qualitative research (case study), involving the teachers of the boarding school of a private university in the interior of the state of São Paulo. The research procedures were: application of questionnaire, interview with semi-structured script and observation of the teaching action at boarding school. The analysis of data (content analysis) sought to characterize the action of the doctor-teacher in the construction of their professional identity, to unveil the didactic-pedagogical and assistance relationships in the development of daily activities, to evaluate the didactic-pedagogical process, to highlight the limits and possibilities At boarding school The triangulation between the actions of the doctor-teacher, the patient and the student will reveal these interrelationships and enable the design of new teaching methodologies in the internship practice.
\end{abstract}

Keywords: Teaching care integration services, internship, preceptorship 


\section{INTRODUÇÃO}

O trabalho docente do profissional médico, em especial no estágio curricular obrigatório em regime de internato, traz, no dia a dia, reflexões e questionamentos sobre os dilemas existentes entre a sua atuação pedagógica e o atendimento ao doente.

A resolução no 3 do Ministério da Educação de 20/06/2014 (BRASIL, 2014) que instituiu as Diretrizes Curriculares Nacionais do Curso de Graduação em Medicina, em seu artigo 24 regulamenta o funcionamento do internato e estabelece que a formação em Medicina incluirá, como etapa integrante da graduação, o estágio curricular obrigatório de formação em serviço, em regime de internato, sob supervisão, em serviços próprios, conveniados ou em regime de parcerias estabelecidas por meio de Contrato Organizativo da Ação Pública Ensino-Saúde com as Secretarias Municipais e Estaduais de Saúde, conforme previsto no art. 12 da Lei no 12.871, de 22 de outubro de 2013.

O treinamento em serviço surge no Brasil no começo da década de 40 , seguindo o modelo de ensino Flexeneriano, adotado nos Estados Unidos. Durante a década de 50 houve um avanço desta metodologia e em 1969, se normatizou a obrigatoriedade de um período prático com características especiais no final da formação acadêmica dos cursos de graduação em Medicina (BRANT, 2008).

De acordo com as Diretrizes Curriculares Nacionais para os Cursos de Graduação em

Medicina

O Internato é o último ciclo do curso de graduação em Medicina, livre de disciplinas acadêmicas, durante o qual o estudante deve receber treinamento intensivo, contínuo, sob supervisão docente, em instituição de saúde vinculada, ou não, à escola médica. (BRASIL, 2014)

Garcia (1972) caracteriza o internato como uma fase de transição entre a condição de estudante e a de médico. Marcondes e Mascaretteli (1998, p.160) preferem conceituá-lo como uma "metodologia de ensino baseada no aprendizado em serviço, obrigatório nos dois últimos semestres de graduação, podendo ocorrer em outros momentos"

As mudanças metodológicas e as Diretrizes Curriculares Nacionais instituídas à partir de 1999, modificaram os objetivos do internato que atualmente vive um processo de reformulação em todos os cursos de medicina do país. Missaka e Ribeiro (2011) acredita que as Diretrizes Curriculares Nacionais mudaram a visão e a imagem do médico do ponto de vista de sua função na sociedade e tipo de formação necessária dentro de paradigmas modernos e afirma:

Essa legislação recomenda a formação de um médico generalista, humanista, crítico e reflexivo, pautado em princípios éticos, capaz de atuar no processo de saúde-doença em seus diferentes níveis de atenção, com responsabilidade social e compromisso com a cidadania. Recomenda também a realização do treinamento em diferentes cenários e níveis hierárquicos de atenção para superar o modelo científico moderno da medicina: formação especializada, fragmentada, centralizada no órgão doente e não no doente, dependente de tecnologia e elegendo o hospital como espaço principal de formação. (MISSAKA; RIBEIRO, 2011, p. 304)

Deve-se considerar o internato não apenas um campo de práticas, mas também um corpo de conhecimentos que exige abordagens pedagógicas inteiramente novas. O contato diário entre o médico-docente, o paciente e o discente tornam este momento propício e íntimo o suficiente para possibilitar uma aprendizagem significativa e substanciosa.

O contato do discente com o paciente neste momento de sua formação torna-se muito próxima e o médico-docente é o principal facilitador na aprendizagem e assistência 
supervisionada. Nesse processo o médico-docente, em sua atuação junto ao aluno, planeja, guia e estimula o discente em seu caminhar, sendo sua presença de suma importância, pois deve oferecer ao aprendiz ambientes que lhe permitam construir e reconstruir conhecimentos. $O$ docente ensina realizando procedimentos técnicos e moderando a discussão de casos. Assume papel de docente-clínico, um profissional que domina a prática clínica e os aspectos educacionais relacionados a ela, transformando-a em ambiente e momento educacionais propícios.

Os dois atores - professor e médico - devem atingir seus objetivos. O primeiro ensinar, capacitar novas gerações de médicos, apresentando adequadamente as situações clínicas, por meio de discussões de casos dos pacientes. O segundo cuidar do doente, garantindo um atendimento digno, humanizado e tecnicamente embasado em preceitos éticos e científicos. Esses dois atores por ocuparem o mesmo espaço físico e o mesmo momento, devem dialogar constantemente. Este diálogo de ações concomitantes traz dificuldades idiossincráticas para o médico-docente no seu dia a dia, haja vista que não se consegue manter uma uniformidade entre as funções e, por vezes, um desses atores se sobrepõe ao outro causando prejuízos para uma ou outra atuação.

A partir dessas considerações a presente pesquisa se justifica, tendo em vista a necessidade de maior entendimento desta triangulação: médico-docente, discente, paciente e, por conseguinte, seja possível propor mudanças da prática docente que propiciem um aperfeiçoamento nas visitas médicas, fortalecendo as convergências e minimizando as adversidades. $O$ distanciamento com perspectivas de mudanças de paradigmas, da visão tecnicista e a incorporação da visão humanista e sociológica do processo saúde-doença e educativo, é algo ainda a ser inquerido e dialogado com os professores médicos para maior conscientização de sua prática médica e docente.

Assim, configuram-se como questões da pesquisa: Qual a percepção do médicodocente sobre seu espaço de assistência e de ensino? - Como se configura a identidade profissional do médico-docente? - Que proposições didático-pedagógicas são assumidas por esses docentes? - Como o médico-docente sistematiza e planeja as visitas médicas acadêmicas visando à qualidade do ensino e do atendimento médico? - Como as dificuldades e limitações se manifestam na prática do médico-docente no espaço do internato?

Buscando responder a tais questões o objetivo geral do trabalho centrou-se em analisar a ação do médico-docente em sua prática pedagógica cotidiana, buscando compreender sua identidade, concepções e experiências educativas.

\section{MÉTODOS}

O trabalho se constitui em uma pesquisa qualitativa, configurando-se como um estudo de caso, envolvendo os docentes do internato de uma Universidade privada do interior do estado de São Paulo. Para Minayo (2010) a abordagem qualitativa possibilita a contextualização dos sujeitos investigados buscando a compreensão dos significados de suas experiências de vida e de suas interpretações sobre o mundo e sobre si mesmos, levando em conta os entendimentos e conflitos em seus depoimentos.

A opção pelo estudo de caso é justificada uma vez que o foco de atenção e investigação da pesquisa está concentrado na figura de sujeitos, ou seja, preceptores-docentes do internato de um curso de graduação em Medicina de uma instituição privada. Foram convidados a participar do estudo todos os professores que atuem no ciclo profissionalizante nas enfermarias de clínica médica, hematologia, cardiologia, nefrologia e pneumologia em ambiente hospitalar.

Para atingir os objetivos propostos foram utilizados os seguintes procedimentos de pesquisa:

1. Pesquisa bibliográfica: que propiciou aprofundar a fundamentação teórica e contextualização do assunto abordado, tendo sido realizado um levantamento das produções 
referente aos temas: educação médica, ensino médico no internato, médico-preceptor, dilemas do ensino médico. 2. Questionário: com questões objetivas (fechadas), respondido por escrito pelos participantes, buscando traçar o perfil dos docentes. 3. Entrevistas com roteiro semiestruturado: as entrevistas foram realizadas a partir de um roteiro pré-determinado, procurando identificar respostas para as questões que norteiam o trabalho. Utilizou-se, com a permissão dos sujeitos da pesquisa, o recurso de gravação de áudio para posterior transcrição. As entrevistas foram pré-agendadas e individuais.

O tratamento e análise dos dados coletados, realizados numa perspectiva qualitativa, tem como referência a análise de conteúdos de Bardin (2009) para a categorização dos resultados. Nesse processo se buscou levantar as inter-relações, identificar tendências gerais e particulares, bem como propor indicativos de reflexão que possam contribuir para a construção da identidade do médico-docente.

Considerando que a pesquisa envolveu contato com seres humanos, o projeto foi aprovado pelo Comitê de Ética de Pesquisa da UNOESTE -protocolo no: 64086017.3.0000.5515.

\section{RESULTADOS}

A parir dos questionários foi possível traçar o perfil dos docentes participantes da pesquisa estão inseridas na tabela 1.

Tabela 1. Caraterização dos participantes.

\begin{tabular}{lcc}
\hline Variável & No & $\%$ \\
SEXO & 3 & 50 \\
Feminino & 3 & 50 \\
Masculino & 6 & $\mathbf{1 0 0}$ \\
Total & & \\
& & \\
IDADE & 1 & 16,6 \\
30 a 35 anos & 2 & 33,4 \\
36 a 40 anos & 2 & 33,4 \\
41 a 45 anos & 1 & 16,6 \\
$>45$ anos & 6 & 100 \\
Total & & \\
& & \\
TEMPO DE ATUAÇÃO DOCENTE & 2 & 33,4 \\
1 a 5 anos & 1 & 16,6 \\
6 a 10 anos & 3 & 50 \\
11 a 15 anos & $\mathbf{6}$ & $\mathbf{1 0 0}$ \\
Total & 6 & \\
& & 66,6 \\
TITULAÇÃO & & 16,7 \\
Especialização & 4 & 16,7 \\
Mestrado & 1 & $\mathbf{1 0 0}$ \\
Doutorado & 1 & \\
Total & $\mathbf{6}$ &
\end{tabular}

A seguir apresentamos algumas categorias levantadas a partir das entrevistas realizadas com os docentes.

\section{1) PERCEPÇÃO DO MÉDICO DOCENTE AO RESPEITO DO SEU ESPAÇO DE ENSINO.}

Os docentes foram concordantes quanto à necessidade de modificar o espaço de ensino com a inserção de recursos tecnológicos conforme discurso do Docente (2)

Por exemplo, se eu preciso ver um RX eu não consigo visualizar esse RX dentro do quarto, eu preciso sair do quarto para olhar no negatoscópio, se eu tenho que ver os 
exames prévios eu não consigo visualizar isto dentro do quarto ne nas condições ideais eu acho que seria uma tela de computador dentro de cada quarto para que a gente conseguisse visualizar todos os exames, tudo isso.

A relação aluno paciente na visão do docente 6 tem impacto na formação e no aproveitamento das visitas médicas em enfermaria e destaca ainda a necessidade de uma visita multiprofissional para garantir uma discussão mais profícua do caso clínico posto, conforme transcrição abaixo

Primeiro você tem que ter um número e uma variabilidade de pacientes razoável, uma proporção de acadêmico por leito no mínimo um pra um, no máximo, perdão um pra um, é o ideal seria que fossem mais leitos por acadêmico inclusive, eu acho que a presença da equipe multidisciplinar engrandece a visita, a presença do fisioterapeuta, a presença da enfermagem na visita, acrescenta, a própria residente acrescenta em via de regra...

Em todas as entrevistas observou-se a preocupação dos docentes com o espaço e conformação da visita médica para sua melhor efetividade e qualidade. A preocupação com a distribuição dos leitos entre os alunos e o tempo dedicado à visita médica ficou patente em todas as entrevistas.

\section{2) CONFIGURAÇÃO DA IDENTIDADE PROFISSIONAL MÉDICO-DOCENTE.}

Os docentes mais velhos não observam conflitos importantes em sua atuação como médico e como docente conforme discurso do docente 5

...eu me sinto relativamente confortável tanto como médico e como docente em todas as duas situações eu pessoalmente não tenho muitos conflitos pessoais eu encaro todas as duas, eu não vejo as duas batendo de frente e sim somando uma a outra, então na verdade em minhas condutas como professor...

Os docentes mais jovens do grupo identificam uma maior dificuldade de exercer sua atividade docente do que médica conforme discurso do docente 3 .

Eu acho meio difícil, eu acho que quando você é só um docente que vem sem ser o médico assistente eu acho mais fácil, ao mesmo tempo tem o papel de que você não tem uma relação medico paciente...

\section{3) PROPOSIÇÕES DIDÁTICOS PEDAGÓGICAS ASSUMIDAS POR ESTES DOCENTES.}

A preocupação com a formação pedagógica e didática aparece nos discursos de todos os docentes conforme discurso do docente 1.

...talvez precise de um pouco mais de didática, entendimento de pedagogia e creio que o mestrado e o doutorado fornecem isso para mim.

Os docentes entrevistados afirmam não terem um conhecimento formal de didática e pedagogia o que gera dúvidas e insegurança em sua ação docente. A necessidade de aprimoramento dá a tônica dos discursos

\section{4) SISTEMATIZAÇÃO E PLANEJAMENTO DAS VISITAS MÉDICAS.}

Dentre os docentes entrevistados dois não realizam um planejamento sistematizado de suas visitas médicas e "aproveitam" o momento da visita para discutir complicações à medida que estas aparecem conforme discurso abaixo do docente 5 . 
...a gente tenta aproveitar melhor o que vai aparecendo, é uma maneira melhor vamos dizer mais, marcante para gente tentar passar alguma coisa daquele caso ... É mais dinâmico, e eu acho mais interessante, eu acho mais a nossa realidade. A nossa realidade não é uma coisa que você programe, ela simplesmente aparece na sua frente.

Os outros quatro docentes fazem um planejamento prévio genérico com objetivos gerais com a finalidade de discutir determinadas patologias de pacientes que estejam internados naquele momento. Em geral os docentes discutem com os alunos determinadas doenças com maior prevalência na população e utilizam como disparador casos de pacientes reais que estejam internados conforme discurso do docente 4.

Perfeito, perfeito. Eu já conheço os casos eu sei, eu sei, eu adequo os casos ao tema que eu quero discutir...

5) DIFICULDADES E LIMITAÇÕES QUE SE MANIFESTAM NA PRÁTICA DOCENTE.

A dificuldade de lidar com a heterogeneidade dos alunos no sexto ano é manifestada pelos docentes conforme discurso do docente 6 .

Eu acho que o que tem incomodado a mim e a vários colegas que eu converso é alguma dificuldade que a gente tem com relação a heterogeneidade do perfil do aluno... alunos que chegam sem a devida maturidade, sem o devido preparo no sexto ano de novo falando que é o meu foco de ação, é isso gera pra gente bastante dificuldade...

Três docentes referiram que o tempo que o aluno fica no estágio supervisionado em clínica médica é insuficiente conforme relato da docente 3 .

...eu gostaria de falar assim, eu gostaria que os alunos tivessem a oportunidade de no meu caso passar mais na enfermaria de clinica medica para que a gente, para que eu conseguisse passar para eles não só conhecimento...

\section{DISCUSSÃO}

O espaço de aprendizagem em uma enfermaria de clínica médica de um hospital assistencial e de ensino tem particularidades e estrutura que muitas vezes não é o ideal, conforme apontado pelos docentes desta pesquisa. A distribuição dos pacientes nos quartos, o acesso às informações dos doentes no momento da visita, o número de alunos por doentes são algumas dificuldades encontradas pelos docentes na sua ação diária no processo de ensino aprendizagem. A necessidade de uma melhor adequação do espaço é patente e certamente pequenas mudanças trariam uma dinamização das visitas médicas. Algo a ser debatido para a constituição do médicodocente são os paradigmas de formação da identidade do médico e da formação do docente.

Fica claro nos discursos dos docentes a importância da vivência e da experiência na construção de sua identidade profissional e na criação da sua imagem como médico e docente que evidentemente, estará em processo no profissional jovem e bem mais acabada no médico docente mais velho. Dispende-se disto a importância da heterogeneidade do grupo de docentes que o aluno tem contato durante o internato para que em sua convivência com os docentes tenha oportunizado ao mesmo a salutar variabilidade de conceitos e identidades prontas e inacabadas. De sorte que o aluno pode através desta vivência construir e reconstruir a sua própria identidade profissional

O internato por tratar-se de aprendizagem em serviço traz em si uma dinâmica que muitas vezes não comporta um planejamento de aula nos padrões acadêmicos. Evidentemente 
que o docente deve traçar objetivos gerais a serem alcançados. Os docentes participantes desta pesquisa em linhas gerais respeitam um planejamento de ensino e buscam ativamente discutir as principais patologias que o médico generalista depara-se em sua atividade diária, os docentes mais jovens deixam esta conduta mais clara em seus discursos.

A capacitação docente, especialmente após a implantação das novas Diretrizes Curriculares (2014), tornou-se um desafio importante para os professores que atuam na formação do futuro profissional no período do internato. Seguindo esta linha de importância da preceptoria na formação do médico, pesquisa realizada por Brant (2008) revela que:

A maioria aponta o compromisso com aprendizagem do aluno $(86,7 \%)$, o conhecimento do papel do preceptor como um formador $(66,7 \%)$ e a capacidade de incentivar o aluno para sua aprendizagem $(66,7 \%)$ como as características mais importantes de um bom preceptor. (BRANT, 2008, p.30)

Observa-se nos discursos dos docentes a falta de preparo acadêmico para a sua ação como docente e a preocupação com a formação contínua. A oferta de cursos de didática e pedagogia direcionada para este público, seria uma solução para os anseios deste grupo que em sua grande maioria aprendeu a ensinar, ensinando. O médico que tem uma formação bastante cartesiana e quando torna-se docente a falta de modelos a seguir, é motivo de stress e insegurança. As palavras destes docentes refletem certamente o pensamento de muitos outros, a busca de modelos de ensino a melhor estruturação física e tecnológica do espaço do internato e a formação contínua dos docentes é o tripé sobre o qual conseguiremos construir as mudanças propostas pela nova diretriz de ensino médico, com visão humanista da medicina.

\section{REFERÊNCIAS}

BARDIN. L. Análise de Conteúdo. Lisboa-Portugal: Edições 70 LDA, 2009.

BRANT, V. Formação pedagógica de preceptores do internato médico: construção de um modelo. Revista Brasileira de Educação Médica, Rio de Janeiro, v. 32, n. 3, Suplemento 2 jul/set, p. 30, 2008

BRASIL, DCN, Resolução no 3, de 20 de junho de 2014 Institui Diretrizes Curriculares Nacionais do Curso de Graduação em Medicina e dá outras providências. 2014

GARCIA, J.C, La educación médica en la América Latina. Washington,D.C.. Organización Panamericana de la Salud, Publicación Científica No. 255,1972.

MARCONDES, E., MASCARATELLI, L.A. O internato na graduação médica. Educação médica. São Paulo, SP: Sarvier.: 1998. p. 149-166.

MINAYO, M.C.S. (Org.). Pesquisa Social: teoria, método e criatividade. 29 ed. Petrópolis, RJ: Vozes, 2010

MISSAKA, H., RIBEIRO,V.M.B. A Preceptoria na Formação Médica: o que dizem os trabalhos nos Congressos Brasileiros de Educação Médica 2007-2009. Revista brasileira de educação médica 35 (3): 303-310; 2011, https://doi.org/10.1590/S0100-55022011000300002. 